EchoGéo

ECHOGEO Sur le Vif | 2009

\title{
Géorgie-Ossétie-Russie. Une guerre à toutes les échelles
}

Julien Thorez

\section{OpenEdition}

Journals

Édition électronique

URL : https://journals.openedition.org/echogeo/10890

DOI : 10.4000/echogeo.10890

ISSN : 1963-1197

Éditeur

Pôle de recherche pour l'organisation et la diffusion de l'information géographique (CNRS UMR 8586)

Référence électronique

Julien Thorez, «Géorgie-Ossétie-Russie. Une guerre à toutes les échelles », EchoGéo [En ligne], Sur le Vif, mis en ligne le 13 février 2009, consulté le 21 septembre 2021. URL : http://

journals.openedition.org/echogeo/10890; DOI : https://doi.org/10.4000/echogeo.10890

Ce document a été généré automatiquement le 21 septembre 2021.

\section{(c) (i) (9)}

EchoGéo est mis à disposition selon les termes de la licence Creative Commons Attribution - Pas d'Utilisation Commerciale - Pas de Modification 4.0 International 


\title{
Géorgie-Ossétie-Russie. Une guerre à toutes les échelles
}

\author{
Julien Thorez
}

La dislocation de l'URSS a considérablement modifié la carte politique de l'Eurasie en donnant naissance en 1991 à quinze Etats indépendants et souverains constitués sur la base des anciennes républiques soviétiques.

Carte de localisation

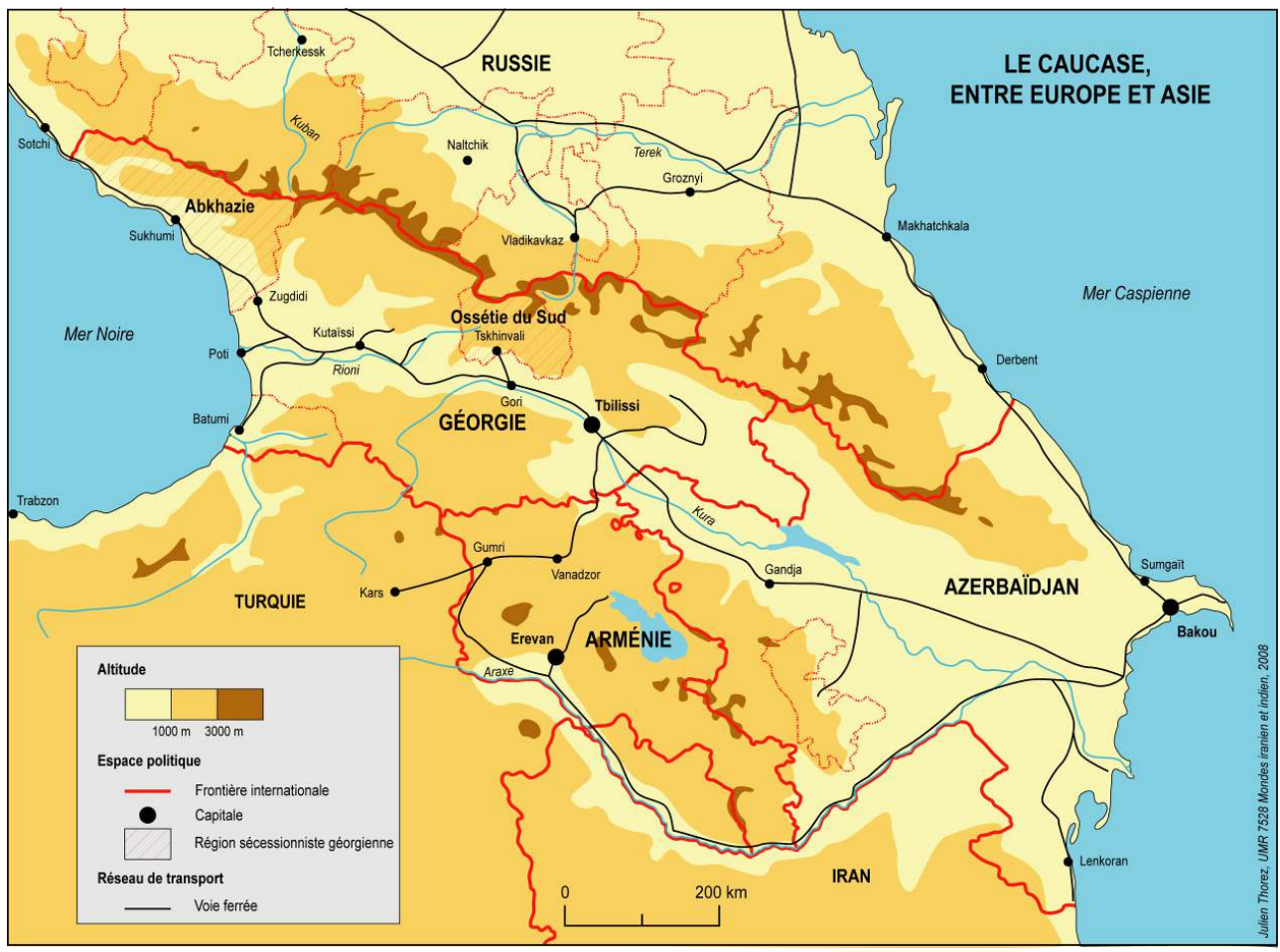


2 L'émiettement de l'espace soviétique s'est prolongé au cours des années 1990, dans un contexte marqué par la généralisation des conflits armés (Lynch, 2002). Certains territoires ont fait sécession, telle la Transnistrie, séparée de facto de la Moldavie, ou dans le Caucase, la Tchétchénie, qui avait déclarée son indépendance en 1991 avant de subir deux guerres l'opposant aux autorités fédérales de la Russie (carte 1). Dans le même temps, des revendications irrédentistes, censées conduire à des translations territoriales entre les républiques nouvellement indépendantes, ont affecté le champ géopolitique post-soviétique. Le Haut Karabakh, région autonome située en Azerbaïdjan mais majoritairement peuplée d'Arméniens, a ainsi été au cœur de la guerre déclenchée en 1988 entre l'Arménie et l'Azerbaïdjan à l'issue de laquelle les forces militaires arméniennes ont contrôlé environ $15 \%$ du territoire azerbaïdjanais. Correspondant à l'apparition de nouvelles dyades ou à un changement du tracé d'une limite inter-étatique, ces différentes modifications frontalières ne s'inscrivent pas dans le droit international : ces évolutions de facto de la carte politique ne débouchent pas sur une reconnaissance internationale des pays ainsi formés ou des frontières ainsi tracées.

Carte 1

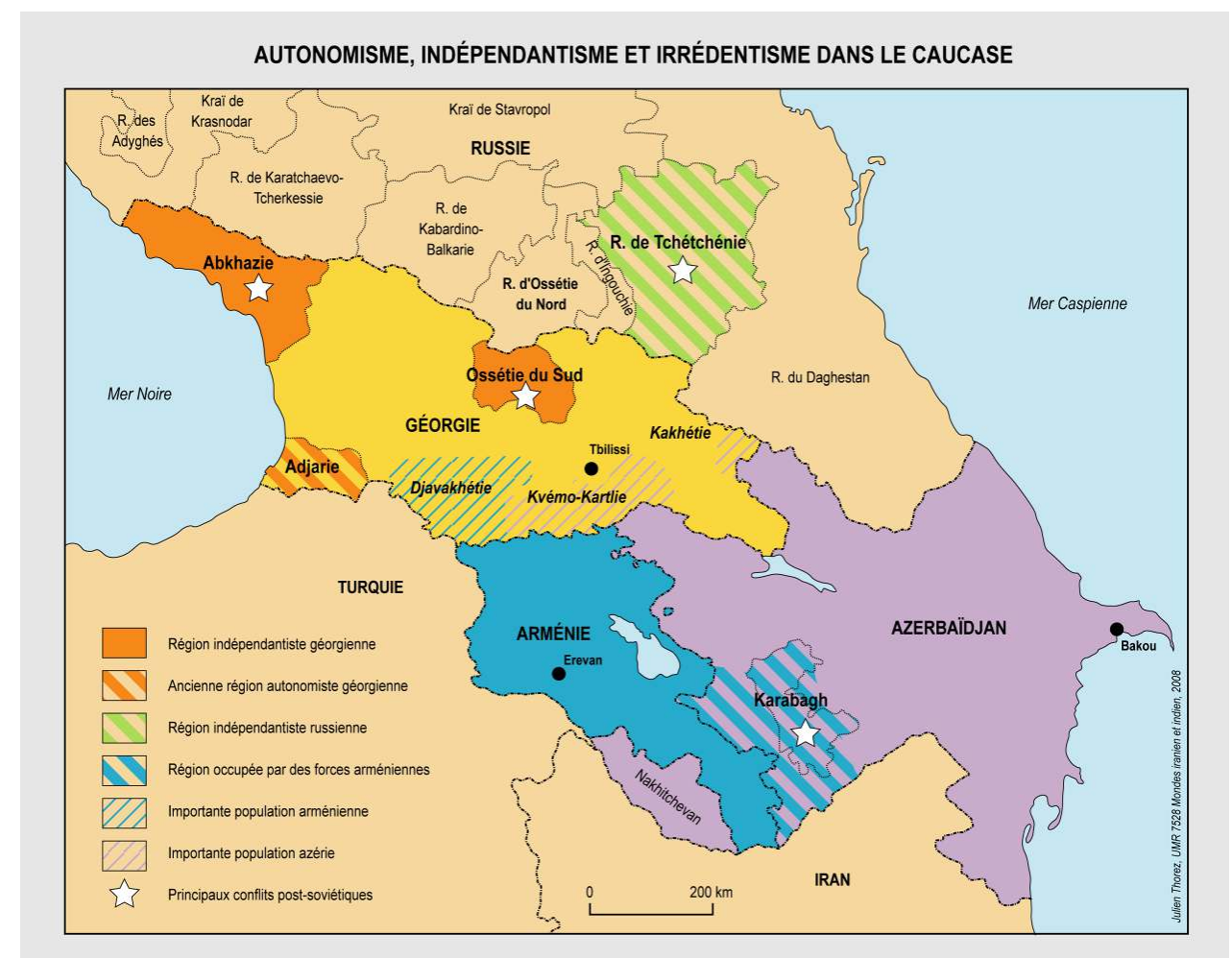

3 Alors que les conflits apparaissaient gelés, une nouvelle guerre s'est déroulée dans le Caucase en août 2008. Mettant en jeu l'intégrité territoriale de la Géorgie, elle a non seulement opposé les forces gouvernementales géorgiennes aux troupes séparatistes d'Ossétie du Sud et d'Abkhazie mais également, fait sans précédent, la Géorgie à la Russie (tableau 1). 
Tableau 1 - Caractéristiques ethno-nationales des principaux protagonistes du conflit de l'été 2008

\begin{tabular}{|l|l|l|}
\hline \multicolumn{1}{|c|}{ Nationalité } & \multicolumn{1}{|c|}{ Langue } & \multicolumn{1}{c|}{ Religion } \\
\hline $\begin{array}{l}\text { géorgienne } \\
\text { ossète }\end{array}$ & caucasienne & christianisme (sauf en Adjarie) \\
abkhaze & iranienne & christianisme majoritaire \\
russe & caucasienne & christianisme majoritaire \\
\hline
\end{tabular}

4 Par delà l'engagement militaire de l'ancienne puissance impériale, ce conflit apparaît comme une rupture dans la politique étrangère de la Russie. Rejetant un élément important de leur doctrine internationale, les autorités de Moscou ont en effet décidé de reconnaître l'indépendance des territoires sécessionnistes sud-caucasiens. La souveraineté de l'Ossétie du Sud et de l'Abkhazie, qui ont respectivement comme dirigeant E. Kokoïty et S. Bagapch, n'est cependant qu'un des enjeux de la guerre. Car ce conflit doit être appréhendé à plusieurs échelles - locale, nationale, macro-régionale et internationale - tant les enjeux paraissent imbriqués et les acteurs directs et indirects multiples. De ce point de vue, la rhétorique employée par les différents belligérants et leurs soutiens pour justifier leur recours à la force armée a de façon significative oscillé entre des discours ancrés dans le contexte caucasien - la Russie serait, par exemple, intervenue pour mettre fin au génocide perpétré par l'armée géorgienne à l'encontre des populations civiles ossètes - et des arguments de portée internationale - dans le cadre de la réactivation des oppositions héritées de la Guerre froide, la Géorgie aurait incarné le camp des démocraties libérales occidentales contre le totalitarisme impérialiste de la Russie.

\section{Un conflit entre répétition et nouveauté}

Le 7 août 2008, l'armée géorgienne bombarde Tskhinvali, capitale de l'Ossétie du Sud, dans le but de reprendre le contrôle de cette portion du territoire national indépendante de facto depuis le début des années 1990. Cette initiative du président géorgien M. Saakachvili met fin à une longue séquence de provocations entre l'armée géorgienne, les forces séparatistes abkhazes et ossètes, et les troupes russiennes stationnant en Ossétie du sud et en Abkhazie dans le cadre d'un mandat de maintien de la paix (ICG, 2008). Préparée et décidée à intervenir en Géorgie, la Russie engage massivement son armée au sud du Caucase tandis qu'un front est ouvert en Abkhazie (carte 2). D'importantes villes (Gori, Poti, Zugdidi) et voies de communications géorgiennes sont occupées par l'armée russienne. La circulation est temporairement interrompue entre l'est et l'ouest du pays et un blocus maritime instauré en Mer noire. Un cessez-le-feu rapide, signé sous l'égide de l'Union Européenne, consacre la victoire militaire de la Russie tout en préservant la Géorgie d'un renversement de régime. Après cinq jours de combats, le retour à la paix a également été favorisé par la défiance des populations géorgiennes vis-à-vis du recours aux solutions militaires. 


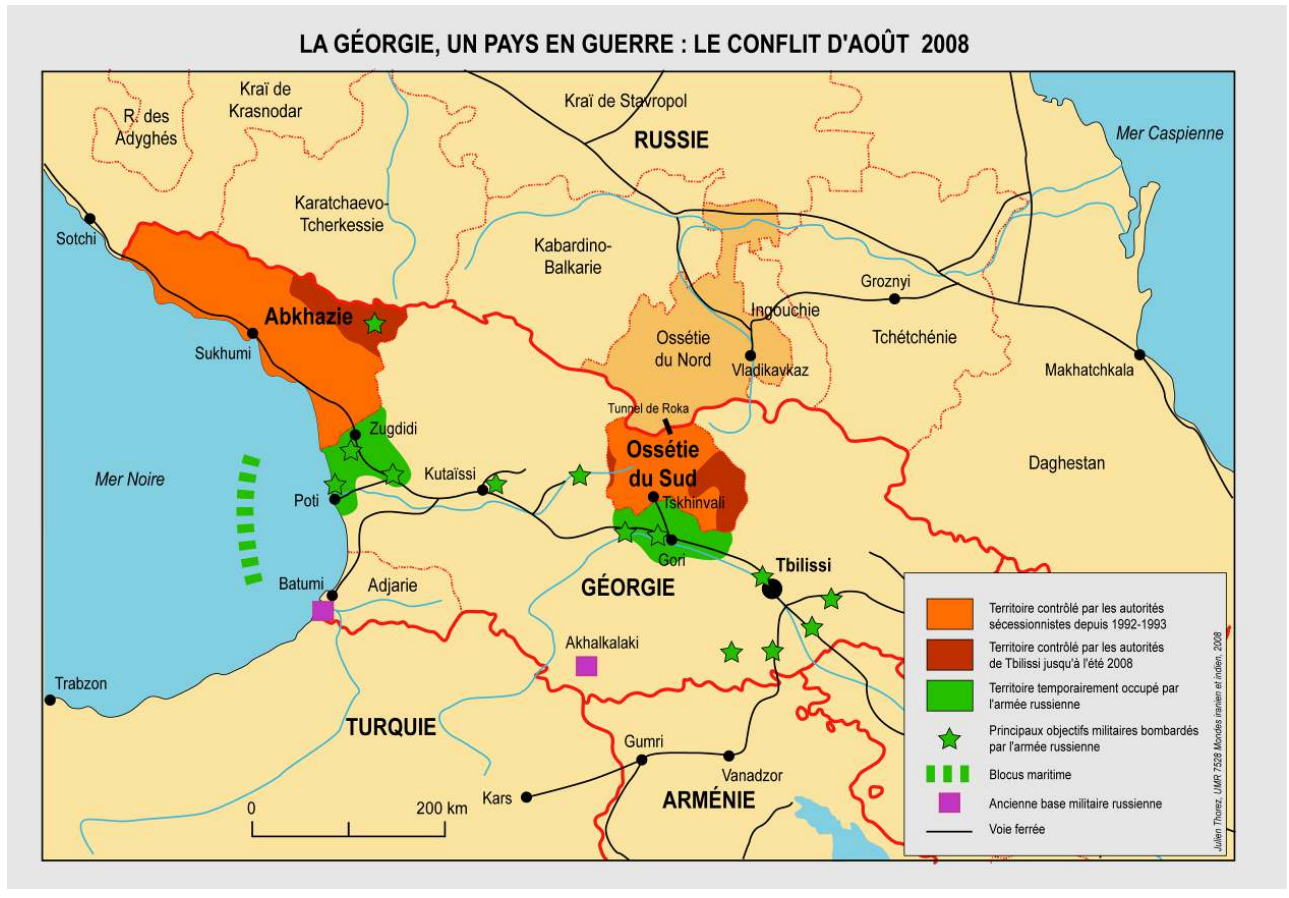

Les lignes de fracture de l'été 2008 semblent avoir ravivé les clivages ouverts durant les conflits qui se sont déroulés sur le territoire de la Géorgie au moment de la soviétisation du Caucase et de la disparition de l'URSS. Des affrontements ont en effet opposés Ossètes et Géorgiens dans les années qui suivirent la révolution bolchevique tandis que la Géorgie, dotée d'un gouvernement menchevik indépendant depuis 1918, était intégrée dans le territoire "soviétique " à la suite de l'invasion de l'armée rouge, qui était soutenue par les Ossètes. Comme de nombreux pays post-soviétiques, la Géorgie a de nouveau connu une période de troubles à la fin des années 1980 et au début des années 1990, dans un contexte caractérisé par l'exacerbation des nationalismes et de la violence politique, et par des mobilisations populaires massives. Rapidement après la déclaration de l'indépendance, le 9 avril 1991, le pays a subi une guerre civile, qui a abouti au renversement du président nationaliste Z. Gamsakhourdia et au retour au pouvoir d'E. Chevardnadze, qui avait été auparavant Premier secrétaire du PC géorgien et Ministre de affaires étrangères de l'URSS. À l'époque, l'intégrité du territoire national était déjà menacée par la guerre qui opposaient Ossètes et Géorgiens depuis le début de l'année 1991 : la volonté d'autonomie croissante des Ossètes - les autorités de Tskhinvali avaient déclaré la séparation de l'Ossétie du Sud d'avec la Géorgie en 1990 et promouvaient son unification avec l'Ossétie du Nord (German, 2006) - se heurtait à la politique des autorités de Tbilissi qui souhaitaient "géorgianiser " le pays et qui avaient abrogé en décembre 1990 le statut autonome de l'Ossétie du Sud. Un accord signé en juin 1992 à Dagomys met un terme aux combats et instaure une force de maintien de la paix à laquelle participe l'armée de la Russie. Toutefois la crise de l'indépendance se prolonge et l'Abkhazie devient le théâtre d'une guerre qui durera de l'été 1992 à l'automne 1993, l'intervention des forces armées géorgiennes répondant notamment à l'adoption par l'Abkhazie de la constitution de 1925 qui assurait l'indépendance de la république par rapport aux autorités de Tbilissi. Alors que les hostilités ont ponctuellement repris en 1998 et en 2001 en Abkhazie et en 2004 en Ossétie du Sud, aucun accord politique n'est venu sanctionner 
ces conflits (Serrano, 2007), dont la guerre de l'été 2008 est dans une certaine mesure la continuation.

7 Malgré ces antécédents dont la mémoire traverse les opinions publiques caucasiennes, la guerre d'août 2008 présente un caractère inédit du fait de l'engagement direct de la Russie dans le conflit. Pour la première fois depuis l'éclatement de l'URSS, la Fédération de Russie s'est opposée militairement à une ancienne république soviétique, la Géorgie, laquelle avait rejoint le monde russe à la fin du XVIII siècle, devant la menace des puissances musulmanes ottomane et persane. Deux siècles plus tard, les enjeux de la guerre traduisent la complexité de la relation post-coloniale entretenue par l'ancienne puissance impériale et la Géorgie.

\section{Les guerres au cœur des transformations post- soviétiques du Caucase}

Outre la redéfinition de la carte politique, les conflits post-soviétiques ont occasionné des modifications importantes des structures sociales et spatiales dans le Caucase du Sud. Les guerres d'Ossétie et d'Abkhazie ont en particulier transformé la population et le peuplement de la Géorgie, dans un contexte marqué par une crise démographique sans précédent. La population géorgienne a en effet reculé de 5,400 M à 4,516 M d'habitants de 1989 à 2006

$-16 \%$.

Figure 1

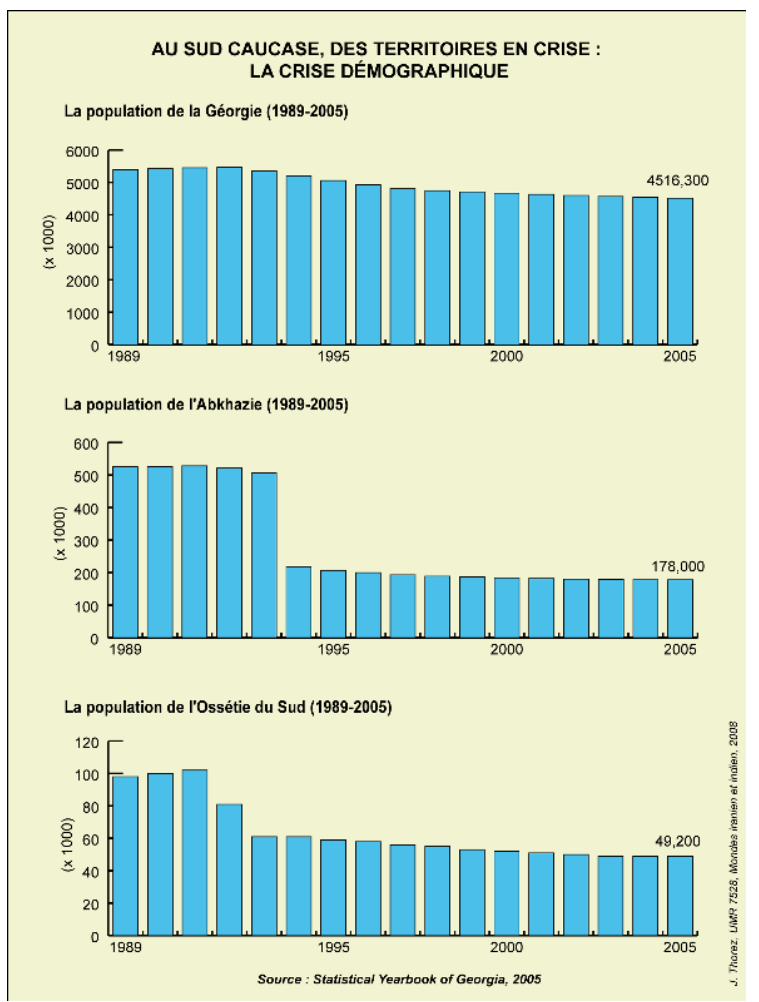

Or, dans les territoires sécessionnistes, le processus de dépeuplement a été encore plus accentué, en raison de la fuite, souvent définitive, des habitants devant les combats. En 
Abkhazie, la population a ainsi été réduite de près de $60 \%$ depuis 1989 , de près de $30 \%$ en Ossétie du Sud (tableaux 2 et 3). Dans le même temps, les équilibres ethniques régionaux ont connu des évolutions sensibles, car la nature des conflits a donné lieu à des mobilités de crise différenciées en fonction de la nationalité des migrants. En particulier, les réfugiés de nationalité géorgienne n'ont pas pu regagner l'Abkhazie, où les effectifs des Géorgiens ont de ce fait chuté de 239000 à 42000 habitants entre 1989 et 2003 (-80\%). À l'inverse, la part des Abkhazes s'est élevée de $17 \%$ à $43 \%$ de la population totale durant les années qui ont suivi le conflit de 1992-1993. Cette homogénéisation de la population du point de vue de la composition nationale est une tendance commune à la quasi-totalité des territoires issus de l'URSS. Toutefois, dans le Caucase du Sud, ce processus a été largement coercitif. De ce point de vue, à travers les dizaines de milliers de réfugiés ayant ralliés la Russie ou le cœur du territoire géorgien, la guerre de 2008a, au moins temporairement, prolongé le phénomène. Si E. Kokoïty a déclaré, la paix revenue, vouloir édifier une société multi-nationale en Ossétie du Sud, sur le modèle qui prévalait à la fin de la période soviétique, en Abkhazie, S. Bagapch s'est ainsi fermement prononcé contre le retour des réfugiés géorgiens de façon à préserver un équilibre ethnique favorable aux Abkhazes. Par ailleurs, durant la guerre, les milices ossètes ont mené des actions répétées contre les villages géorgiens d'Ossétie du Sud. Remettant en cause la coexistence séculaire des deux populations, ces opérations qui visaient le départ définitif des Géorgiens ont été conduites sans que l'armée russienne n'intervienne face à cette forme de purification ethnique.

Tableau 2 - La population de l'Abkhazie (1926-2003)

\begin{tabular}{|c|c|c|c|c|c|c|c|c|c|c|}
\hline \multirow[b]{2}{*}{ Abkhazes } & \multicolumn{2}{|c|}{1926} & \multicolumn{2}{|c|}{1939} & \multicolumn{2}{|c|}{1959} & \multicolumn{2}{|c|}{1989} & \multicolumn{2}{|c|}{$2003^{* *}$} \\
\hline & 55918 & $27,8 \%$ & 56197 & $18,0 \%$ & 61193 & $15,1 \%$ & 93267 & $17,8 \%$ & 94606 & $43,8 \%$ \\
\hline Géorgiens & $24588 *$ & $12,2 \%$ & 91967 & $29,5 \%$ & 158221 & $39,1 \%$ & 239872 & $45,7 \%$ & 42355 & $19,6 \%$ \\
\hline Arméniens & 25677 & $12,8 \%$ & 49705 & $15.9 \%$ & 64425 & $15,9 \%$ & 76541 & $14,6 \%$ & 44870 & $20,8 \%$ \\
\hline Russes & 12553 & $6,2 \%$ & 90201 & $19,3 \%$ & 86715 & $21,4 \%$ & 74914 & $4,4 \%$ & 23420 & $10,8 \%$ \\
\hline Grecs & 14045 & $7,0 \%$ & 34621 & $11.1 \%$ & 9101 & $2,2 \%$ & 14664 & $2,8 \%$ & 1486 & $0,7 \%$ \\
\hline $\begin{array}{l}\text { Population } \\
\text { totale }\end{array}$ & 201016 & & 311885 & & 404738 & & 525061 & & 215972 & \\
\hline
\end{tabular}

Sources : recensements de la population de l'URSS et de l'Abkhazie autonome

* Au recensement de 1926, plusieurs populations par la suite intégrées dans la catégorie « Géorgiens » ont été comptées séparément, tels les Mingréliens (40 989 personnes, soit 20,4 \% des effectifs totaux) ou les Svanes, de sorte que les Abkhazes apparaissaient comme la population nationale la plus nombreuse de la RSS d'Abkhazie.

** Ces données sont produites par la direction des statistiques de la république d'Abkhazie. Le département des statistiques du Ministère du développement économique de la Géorgie estimait pour sa part que la population de l'Abkhazie atteignait 179000 habitants en 2003 et qu'elle continuait lentement à décroître. 
Tableau 3 : La population d'Ossétie du Sud (1926-2005)

\begin{tabular}{|l|c|c|c|c|c|c|c|c|c|c|}
\hline & \multicolumn{2}{|c|}{1926} & \multicolumn{2}{|c|}{1939} & \multicolumn{2}{c|}{1959} & \multicolumn{2}{c|}{1989} & \multicolumn{2}{c|}{$2005^{*}$} \\
\hline Ossètes & 60351 & $69,1 \%$ & 72266 & $68,1 \%$ & 63698 & $65,8 \%$ & 65233 & $66,2 \%$ & 45000 & $64 \%$ \\
Géorgiens & 23538 & $26,9 \%$ & 27525 & $25,9 \%$ & 26584 & $27,5 \%$ & 28544 & $28,9 \%$ & 17500 & $25 \%$ \\
Russes & 157 & $0,2 \%$ & 2111 & $2,0 \%$ & 2380 & $2,5 \%$ & 2128 & $2,1 \%$ & $?$ & \\
$\begin{array}{l}\text { Population } \\
\text { totale }\end{array}$ & 87375 & & 106118 & & 96807 & & 98527 & & 70000 & \\
\hline
\end{tabular}

Sources : recensements de la population de l'URSS

* La population de l'Ossétie du Sud n'a pas été recensée depuis 1989. Son dénombrement repose donc sur des estimations, lesquelles montrent une forte diminution des effectifs et une certaine stabilité des équilibres ethniques.

La guerre d'août 2008 a également remis en cause le compromis politique et territorial qui avait prévalu depuis le début des années 1990 et qui avait donné lieu à la formation de plusieurs « zones grises » propices aux mobilités informelles et illégales. L'Ossétie du Sud était ainsi devenue une interface majeure entre la Russie et la Géorgie, tandis que l'Abkhazie demeurait en marge des flux méridiens, du fait de la fermeture des frontières (Thorez, 2004) (carte 3). Alors que les relations dégradées et incertaines entre la Russie et la Géorgie rendaient le franchissement de la frontière difficile sur la route militaire de Géorgie, qui relie Tbilissi à Vladikavkaz par le col de la Croix $(2379 \mathrm{~m})$, les flux se sont reportés sur l'itinéraire ossète, qui emprunte le tunnel de Roka, en raison de la souplesse des contrôles effectués aux frontières du territoire séparatiste par les douanes géorgiennes et russiennes (Radvanyi, 2002).

\section{Carte 3}

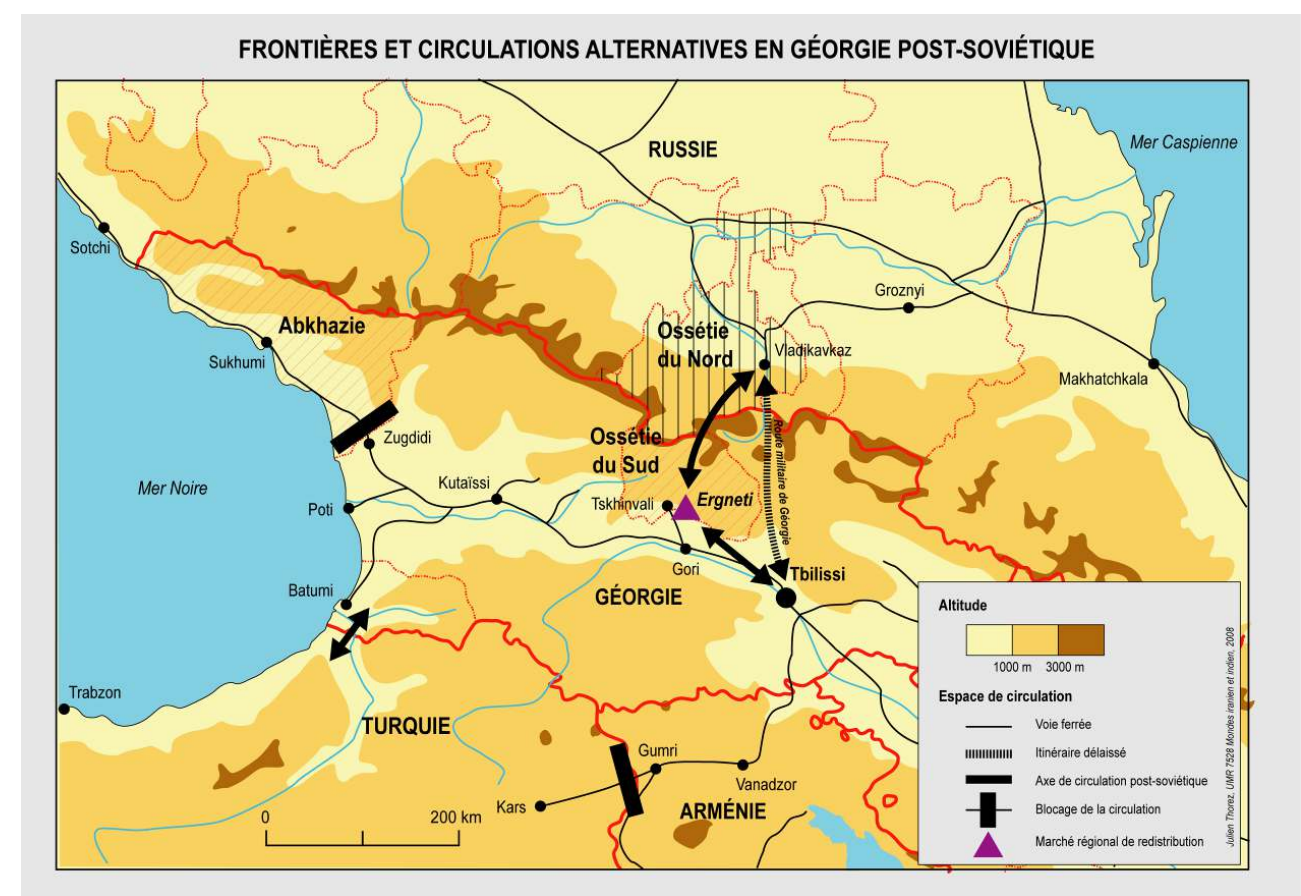

11 Au sud-est de Tskhinvali, un vaste bazar situé à Ergneti assurait un relais logistique efficace entre les marchés géorgien et russien: par cette voie, des carburants, des 
céréales, du tabac arrivaient de Russie tandis que les Géorgiens exportaient des fruits et des légumes ainsi que de l'alcool. Ce compromis intéressait les autorités d'Ossétie du Sud, lesquelles s'enrichissaient en contrôlant ces trafics fructueux, de même que la Géorgie et la Russie, dont les échanges économiques se maintenaient malgré les tensions et des législations contraignantes. Alors que l'établissement de postes de contrôle en 2004, à la suite d'une intervention géorgienne destinée à limiter les ressources des indépendantistes ossètes, avait déjà réduit les échanges, la guerre a mis fin à cette géographie informelle, en donnant corps à la frontière méridionale de l'Ossétie du Sud.

\section{La Géorgie en quête d'unité}

12 En accédant à l'indépendance en 1991 à la suite d'un mouvement nationaliste puissant, la Géorgie a hérité des frontières tracées dans le cadre de la politique soviétique d'aménagement du territoire. Toutefois, à la différence des républiques d'Asie centrale, le pays ne connaissait pas une existence inédite. L'Etat revendiquait une continuité avec la première indépendance de la Géorgie moderne. Il pouvait en outre s'appuyer sur une rhétorique qui valorisait une histoire de plusieurs siècles et qui soulignait l'unité et l'unicité de la nation géorgienne. En dépit de cet ancrage historique et territorial, la question nationale est restée sensible au cours de la transformation post-soviétique. La Géorgie indépendante a notamment été confrontée à l'héritage de la politique des nationalités conduite par les autorités tsaristes puis soviétiques (Cadiot, 2007). Le maintien de la distinction entre la nationalité et la citoyenneté traduit l'appropriation d'un élément important de ce legs par les différentes composantes de la société. Mais les autorités ont dû composer avec la présence de plusieurs entités autonomes dont l'existence tenait à la concrétisation de la construction des catégories nationales et à la territorialisation de la reconnaissance de droits aux nationalités par les autorités bolcheviques: les républiques autonomes d'Abkhazie et d'Adjarie, la région autonome d'Ossétie du Sud (carte 1) ${ }^{1}$. Dans les années 1990, les dirigeants nationalistes, au premier rang desquels Z. Gamsakhourdia, ont été incapables de gérer, autrement que par la violence, cette diversité nationale, politique et territoriale qui contrecarrait leur visée, tandis que des conceptions nationalistes de nature comparable animaient les dirigeants ossètes et abkhazes. Mais le problème de l'intégrité du territoire géorgien posée par le conflit de l'été 2008 renvoie également à une conception de la nation, formulée dès le XIX ${ }^{e}$ siècle par les intellectuels nationalistes (Gordadze, 2001). Opposant l'autochtonie des Géorgiens au statut d'hôte ou d'invité reconnu aux concitoyens des autres nationalités, elle questionne les contours du territoire mais surtout la structure de l'Etat, c'est-à-dire l'organisation administrative et politique du territoire géorgien. La prégnance de cette conception explique d'ailleurs la reconnaissance par les autorités de Tbilissi de l'autochtonie des Abkhazes dans les années 1990 pour légitimer le maintien de la république autonome d'Abkhazie au sein de la Géorgie (Gordadze, 2001).

Dans ce contexte politique et territorial complexe, les autorités géorgiennes ont récemment modifié leur approche de l'Etat et du territoire, en conduisant une politique de modernisation et d'unification depuis l'arrivée au pouvoir de M. Saakachvili au cours de l'hiver 2003-2004. A travers son itinéraire personnel, celui-ci a incarné cette volonté de changement, de même que le rajeunissement spectaculaire du personnel politique. Plus fondamentalement, pour les nouveaux dirigeants, la modernisation de l'Etat, condition de la sortie de la crise post-soviétique, implique l'exercice d'une souveraineté pleine et 
entière du gouvernement de Tbilissi sur l'ensemble du territoire géorgien. Cette orientation s'est donc traduite par la remise en cause de l'autonomie concédée à plusieurs régions durant la présidence d'E. Chevardnadze du fait de la déliquescence de l'Etat. L'administration de l'Adjarie, région frontalière avec la Turquie, relève de nouveau des compétences des autorités centrales, après le départ provoqué du dictateur local A. Abachidze vers la Russie. De même, en Kvemo-Kartlie et en Djavakhétie, où résident d'importantes populations arméniennes et azéries, le système de gestion autonome impliquant à bien des égards les autorités azerbaïdjanaises et arméniennes s'efface au profit du gouvernement géorgien, non sans provoquer des tensions ethniques (Cornell, 2002; Serrano, 2007) (carte1). Ce règlement de l'autonomie des régions méridionales renforce l'unité de la Géorgie et contraste avec les tensions qui caractérisent les frontières septentrionales où la confrontation des ambitions unificatrices géorgiennes et des projets sécessionnistes ossètes et abkhazes a été d'autant plus marquée, que les dirigeants séparatistes, soutenus par la Russie, ont adopté des positions fermes face à la politique géorgienne. Quoi qu'il en soit, le conflit déclenché par le gouvernement géorgien s'inscrivait dans la politique de lutte contre la fragmentation de l'Etat et du territoire, dont il aurait pu constituer, en cas de victoire militaire, une étape avancée. Le budget de la défense a significativement décuplé au cours des dernières années, en raison des investissements réalisés dans l'acquisition d'armements défensifs mais également offensifs (Serrano, 2008).

De façon plus conjoncturelle, du point de vue du calendrier politique géorgien, les événements de l'été 2008 ont succédé à une période de contestation de la légitimité de M. Saakachvili, marquée par d'importantes manifestations à l'automne de 2007 et la tenue d'élections présidentielles et législatives anticipées en 2008, dont les résultats ont été dénoncés par les partis de l'opposition. Si le président géorgien a toujours bénéficié d'un socle de partisans, cette situation a constitué un motif d'inquiétude quant à la stabilité du régime et à la popularité des politiques mises en œuvre par celui-ci. Dans ce contexte, le déroulement de la guerre et les conditions du cessez-le-feu ont, dans une certaine mesure, garanti la survie politique de M. Saakachvili, en dépit des vives critiques de l'opposition et de l'hostilité des dirigeants de la Russie. En revanche, la guerre a conduit à une rétraction du territoire effectivement administré par les autorités de Tbilissi, ce qui traduit l'échec de l'initiative géorgienne à l'échelle nationale. Les régions de l'Abkhazie et de l'Ossétie du Sud qui étaient demeurées sous contrôle géorgien après les conflits des années 1990 - les gorges du Kodori, la région d'Akhalgori - ont été perdues au cours de l'été 2008. De surcroît, les frontières méridionales de l'Abkhazie et de l'Ossétie du Sud connaissent une fonctionnalisation accrue qui tend à les ossifier et à consolider les effets de disjonction au sein du territoire géorgien. Impliquant des risques politiques élevés, la politique d'unification de la Géorgie et de modernisation de l'Etat a donc présenté des résultats contradictoires. Les autorités de Tbilissi ont enrayé la dynamique de fragmentation au sud, mais leurs décisions semblent avoir accéléré le dépeçage du territoire national sur son flanc septentrional.

\section{Russie vs Géorgie: une situation post-coloniale dégradée}

15 La reconnaissance de l'indépendance de l'Abkhazie et de l'Ossétie du Sud constitue une évolution majeure de la politique de la Russie dans le Caucase (carte 4). Malgré un soutien 
aux autonomistes d'Abkhazie et d'Ossétie du Sud qui était conçu comme un instrument du maintien de l'influence de la Russie dans le Caucase du Sud, les autorités de Moscou s'étaient toujours prononcées contre la remise en cause de l'intangibilité des frontières, laquelle étaient inscrite dans les accords signés à l'issue des conflits du début des années 1990. Cette décision, qui pour de nombreux observateurs s'apparente à une réponse à la reconnaissance de la souveraineté du Kosovo, semble pourtant donner du crédit aux revendications indépendantistes nord-caucasiennes, notamment tchétchènes, et ainsi représenter une prise de risques de la part de la Russie. En ce sens, elle souligne la volonté intense de la Russie de modifier les équilibres géopolitiques dans le Caucase. Sera-t-elle pour autant plus productive que la politique menée depuis les indépendances pour réduire les aspirations de la Géorgie à s'émanciper de l'ancienne puissance impériale?

Carte 4

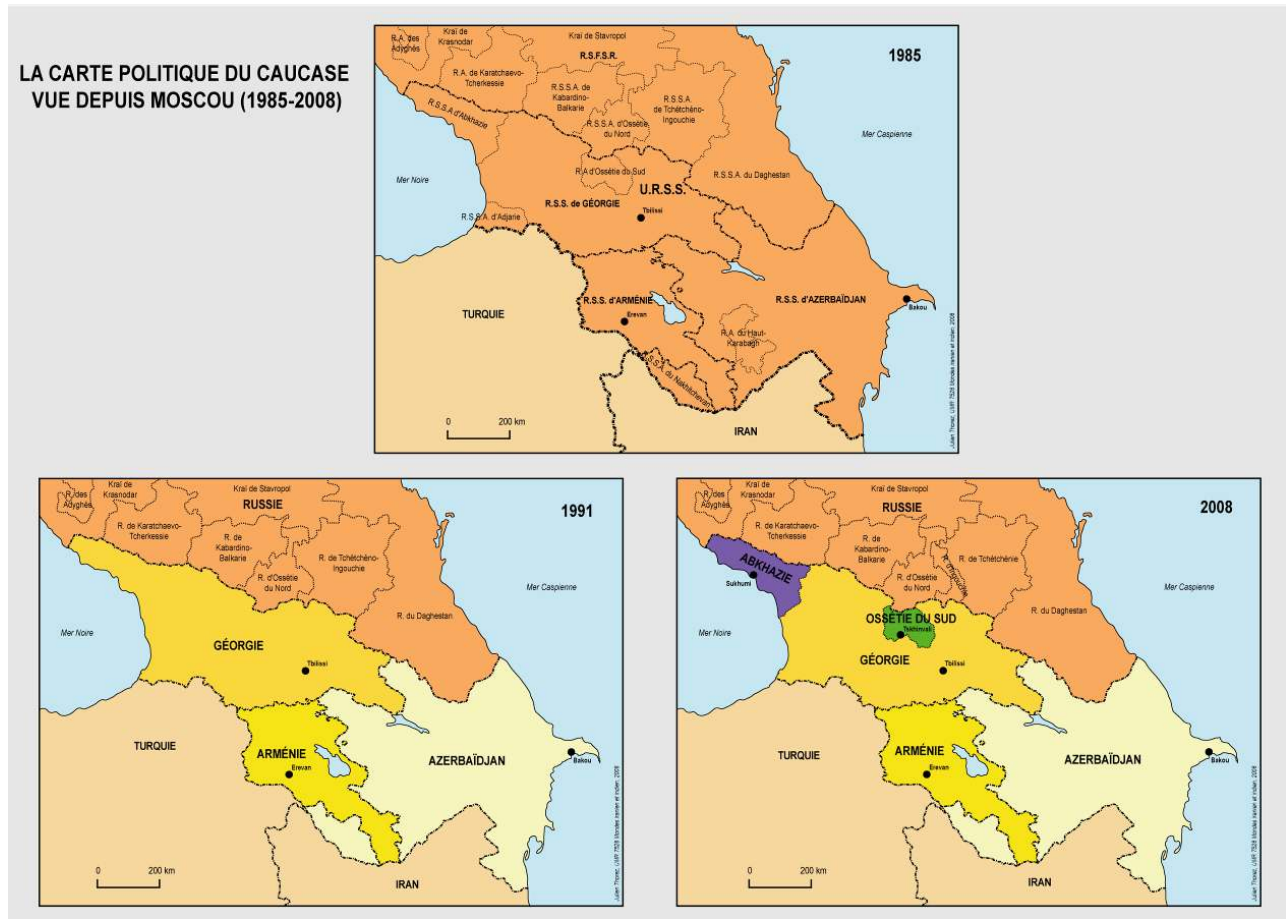

Depuis le démantèlement de l'URSS, la Russie et la Géorgie n'ont en effet pas construit de relations bilatérales solides et apaisées, en raison de leurs ambitions géopolitiques divergentes et de la mise en œuvre récurrente de stratégies fondées sur la tension dans leurs pratiques politiques. Les autorités russiennes souhaitent conserver un rôle dominant au Caucase du Sud, en dépit de la rétraction de l'aire de compétence du pouvoir moscovite consécutive à la disparition de l'URSS. Or, du point de vue de la Russie, ce mouvement de repli politique s'inscrit dans une dynamique plus globale de recul de l'influence russe dans le Caucase. Dans cette marge méridionale du foyer de peuplement russe, la population de nationalité " russe » voit en effet sa part reculer et ses effectifs diminuer. Engagé depuis les années 1960-1970 en Géorgie, en Arménie et en Azerbaïdjan, ce processus affecte également les régions situées dans le Caucase du Nord au sein de la Fédération de Russie, en particulier la Tchétchénie, l'Ingouchie et le Daghestan (cartes 5 et 6) ${ }^{2}$. 
Carte 5

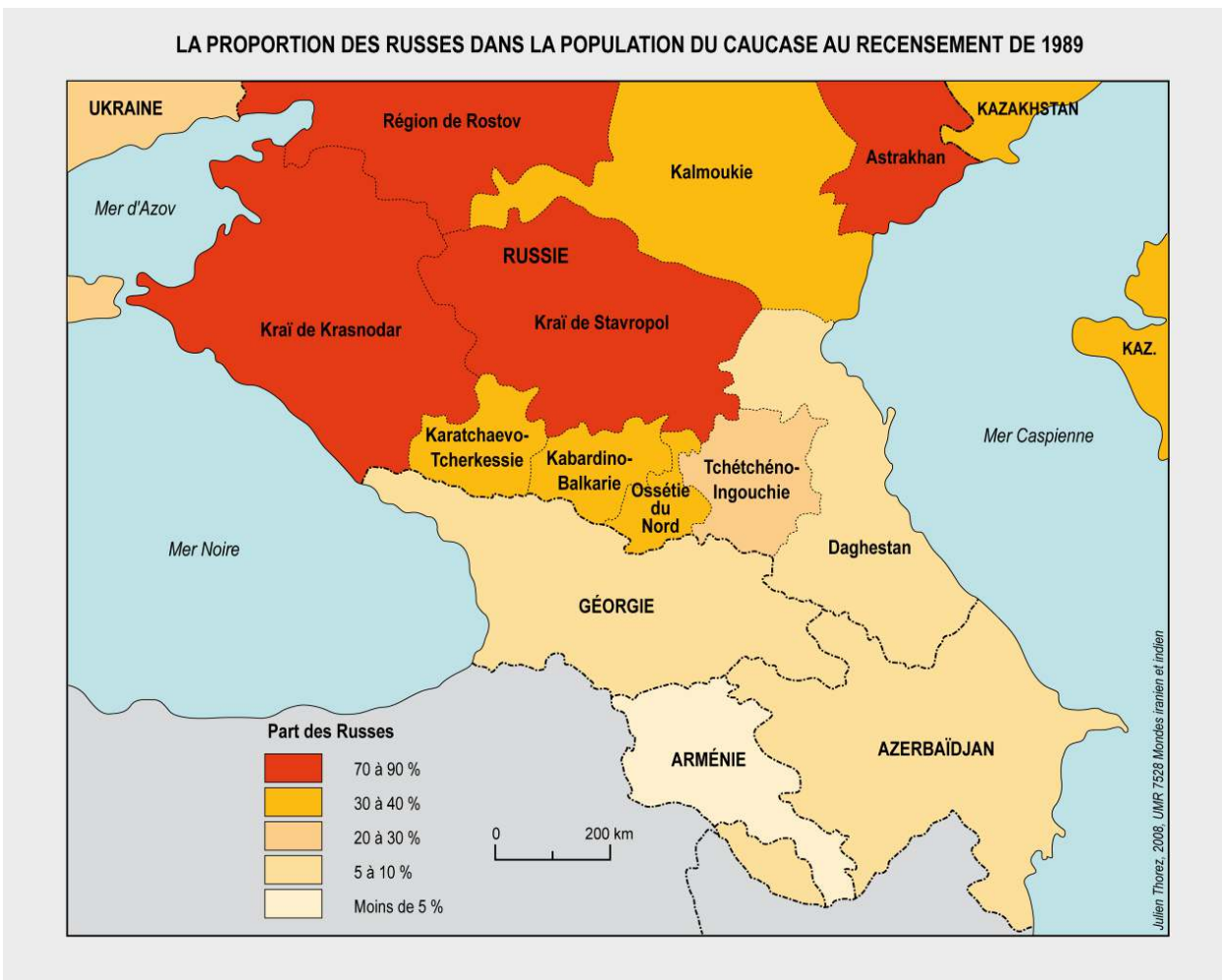

Carte 6

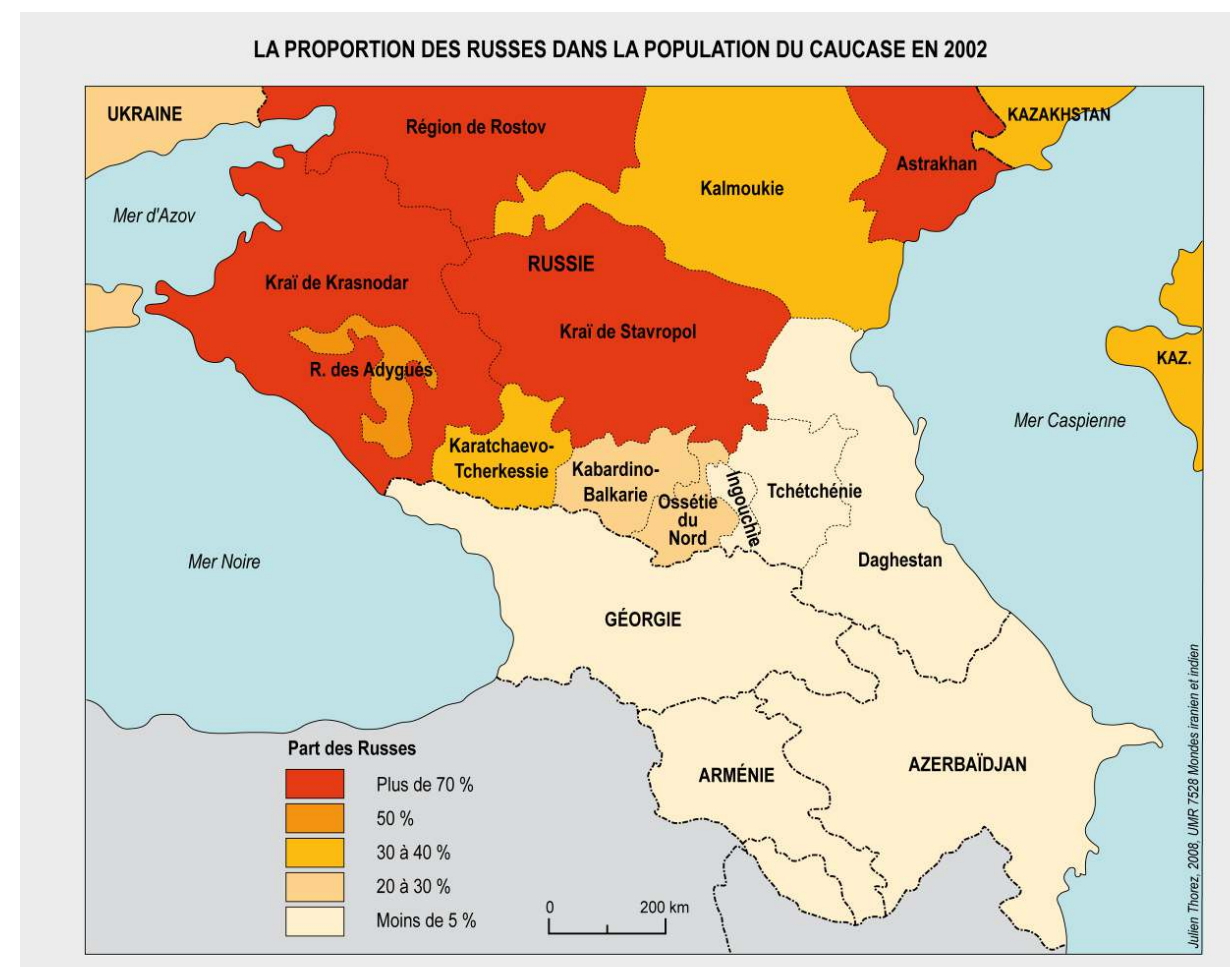

De son côté, la politique étrangère de la Géorgie, qui vise à s'affranchir de la Russie, repose sur une doctrine indépendantiste mais surtout sur la recherche de partenariats 
avec les pays occidentaux, malgré l'adhésion du pays à la CEI en 1993 (Serrano, 2007). De ce fait, les liens se sont distendus, d'autant plus que l'approvisionnement des forces indépendantistes et islamistes tchétchènes et nord-caucasiennes a largement transité par le territoire géorgien. Dans ce contexte, des tensions inter-étatiques sont régulièrement apparues, notamment à l'occasion du partage des infrastructures et du démembrement des institutions soviétiques. La "républicanisation» de l'industrie ou des transports, menée suivant le principe de l'attribution aux nouveaux pays indépendants des équipements présents sur leur territoire, a cependant donné lieu rapidement à des accords internationaux. En revanche, le domaine militaire a été un élément de discorde, en raison de la situation géostratégique de la Géorgie. De surcroît, le pays recelait plusieurs installations d'importance et Tbilissi était le siège du commandement militaire soviétique pour la Transcaucasie. Aussi n'est-ce qu'en 2005 qu'un accord a été signé sur le retrait des troupes russiennes des bases de Batumi et de Akhalkalaki, après des négociations laborieuses (carte 2).

18 Pour régler ses nombreux différends avec la Géorgie, la Russie a eu recours de façon répétée à des pressions et à des sanctions, sans exclure la possibilité de faire usage de la force. Cette politique ainsi que des provocations réciproques ont conduit à une dégradation tendancielle des relations entre les deux pays, accentuée depuis l'arrivée au pouvoir de M. Saakachvili. En 2006, en réponse à l'arrestation de militaires accusés d'espionnage, la Russie a ainsi décidé de suspendre les liaisons aériennes et routières à destination ou en provenance de la Géorgie, de même que les transferts d'argent réalisés par les nombreux migrants de travail. Cet embargo signifiait également l'interruption des importations des produits géorgiens, en particulier des vins et des eaux minérales, pourtant réputés sur le marché russien. Justifiant les craintes géorgiennes, cette politique fondée sur la tension et les menaces se révèle inefficace : la Géorgie n'a procédé à aucune inflexion durable de son positionnement international en faveur de la Russie.

Plus fondamentalement, les imbrications sociales et économiques héritées du passé tsariste et soviétique impliquent néanmoins pour les dirigeants de la Russie et de la Géorgie de coopérer dans le cadre renouvelé de la transition géopolitique post-soviétique. La Russie demeure un des principaux partenaires économiques de la Géorgie et d'importantes entreprises russiennes disposent d'intérêts dans le pays, notamment dans le secteur de l'électricité. Par ailleurs, une part importante et croissante de la population géorgienne réside de façon permanente ou temporaire en Russie, ce qui correspond aux schémas classiques des configurations post-coloniales. Au recensement de 2002, on comptait 198000 Géorgiens (contre 130000 au recensement de 1989), contingent auquel il faut adjoindre la masse des migrants non-enregistrés, de sorte que l'on estime que la diaspora géorgienne comprend entre 800000 et 1000000 de membres (Iskanderian, 2004). Durant les principaux épisodes de tension (2002, 2004, 2006), la situation de cette population a été fragilisée par des mesures gouvernementales discriminatoires et par l'hostilité de la partie de la population russe acquise aux préjugés xénophobes et racistes. En tout état de cause, la diaspora assure des transferts d'argent conséquents, qui introduisent une dépendance économique vis-à-vis de l'ancienne métropole et qui questionnent la place de la Géorgie dans l'espace mondialisé, entre Nord et Sud. En ce sens, bien que moins médiatisée que les divergences géopolitiques, elle se trouve au cœur de la redéfinition des relations entre la Russie et la Géorgie 


\section{Souverainisme ou irrédentisme ? L'Abkhazie et l'Ossétie duSud face à la Russie}

20 Malgré la reconnaissance de l'indépendance de l'Ossétie du Sud et de l'Abkhazie ${ }^{3}$, la question du rattachement à moyen terme des régions sécessionnistes géorgiennes à la Fédération de Russie reste ouverte, en raison de la dynamique intégratrice en cours sur leur frontière septentrionale. La Russie, à travers la politique de l'Etat fédéral et celle des régions, assure un soutien politique, économique et militaire aux nouveaux "pays indépendants » qui recouvre l'ensemble des compétences étatiques jusqu'au personnel politique et administratif - l'administration de l'Ossétie du Sud comprend des membres de l'administration de la Russie. Les accords signés à l'automne 2008 reconnaissent l'adoption du rouble comme monnaie officielle par l'Abkhazie et l'Ossétie du Sud. Du point de vue géostratégique, ils prévoient l'assistance militaire de la Russie et le stationnement permanent, dans ce cadre, de l'armée russienne au Caucase du Sud.

21 Cette politique s'inscrit dans le prolongement de l'action menée depuis les années 1990 pour soutenir non sans ambiguïté les régions indépendantistes. Outre sa dimension militaire, la projection de la Russie sur le rebord méridional du Caucase a en effet pris la forme de communautés de ressortissants de la Fédération de Russie, constituées à la suite de l'attribution massive de passeports russiens aux habitants d'Ossétie du Sud et d'Abkhazie (German, 2006) ${ }^{4}$. Apparue en violation de la souveraineté de la Géorgie au moment de la disparition de l'URSS et surtout depuis 2000-2001, cette communauté de ressortissants extra-territoriaux a permis à la Russie d'instrumentaliser la population «russophone» et de justifier son intervention militaire durant l'été $2008^{5}$. Le principe équivoque de cette double citoyenneté a été récemment réaffirmé, en dépit des indépendances. Il traduit les ambiguïtés de la politique de la Russie mais également des revendications des dirigeants de l'Ossétie du Sud et de l'Abkhazie. Le mouvement national abkhaze, dont la doctrine a été élaborée dans le cadre d'institutions soviétiques «nationales» comme l'Académie des sciences, envisage le développement indépendant du pays, mais la région avait déjà dans les années 1970 demandé son rattachement à la Russie. De même, en Ossétie du Sud, la tenue d'un referendum sur l'indépendance en 1992 et en 2006 n'élimine pas la perspective d'une unification avec l'Ossétie du Nord, ancienne revendication des sécessionnistes.

Quoiqu'il en soit, l'ancrage de l'Abkhazie et de l'Ossétie du Sud dans le monde russe tend à s'affirmer à travers l'insertion croissante des deux territoires caucasiens dans l'espace russien. Entre la Russie et l'Abkhazie, l'ouverture de la frontière succède à une situation de blocage. Des travaux ont été engagés, à l'initiative des autorités russiennes, pour rénover les infrastructures de transport et faciliter la circulation civile et militaire. Aussi la voie ferrée littorale, qui raccorde l'Abkhazie au réseau russien, a-t-elle été rouverte. Dans une perspective comparable, grâce à la remise en exploitation de l'aéroport de Sukhumi, la toute nouvelle compagnie aérienne « nationale » opère des liaisons régulières à destination des villes du Caucase du Nord, en dépit de l'opposition des autorités géorgiennes. La dynamique intégratrice tient également à la volonté des investisseurs russiens d'exploiter le potentiel touristique de l'Abkhazie. Ancienne riviera soviétique, celle-ci se situe dans la continuité de la région de Sotchi, qui accueillera les jeux olympiques d'hiver en 20146. Or, bien que délaissée après la guerre de 1992-1993, l'Abkhazie comprend plusieurs stations balnéaires réputées (Gagra, Pitsunda, etc.) et 
recèle plusieurs hauts-lieux tel le lac Ritsa, lesquels justifient la réapparition récente d'un flux touristique depuis la Russie. Ces éléments donnent à penser que la reconnaissance de l'indépendance des régions géorgiennes par la Russie annonce des recompositions territoriales qui posent la question du passage d'une indépendance de facto à une intégration de facto au sein de la Fédération de Russie.

\section{Des rivalités géopolitiques mondiales : le Caucase au cœur de la nouvelle « Guerre froide » ?}

Durant la guerre de l'été 2008, une lecture bipolaire de l'affrontement s'est imposée dans les discours diplomatiques et dans l'espace médiatique. La Géorgie a été largement appréhendée comme un pays européen démocratique tandis que la Russie a été associée aux stéréotypes liés à l'Union soviétique, malgré l'adoption par les deux pays des principes de l'économie de marché et de la démocratie depuis leur indépendance. Dans la pratique, la Russie ne correspond pas à un archétype de démocratie. Mais la Géorgie s'est également éloignée des intentions affichées par M. Saakachvili à son arrivée à la tête de l'Etat (personnalisation du pouvoir, répression violente de manifestations en 2007, organisation controversée des élections présidentielles et législatives anticipées en 2008). Finalement, plus qu'une confrontation idéologique et politique, cette nouvelle "guerre froide » s'apparente à une opposition géopolitique portant sur la redéfinition de la place des puissances régionales et mondiales dans l'ancienne URSS. Soutenue par les États-Unis et l'Union Européenne qui désirent étendre leur influence dans la région, la Géorgie souhaite s'ancrer dans l'espace géopolitique occidental, en intégrant l'OTAN et l'UE, et ainsi suivre la trajectoire post-soviétique des Pays baltes. De son côté, la Russie, qui conteste l'élargissement des organisations supra-étatiques occidentales nées durant la Guerre froide, a la volonté de conserver une position dominante dans son ancien empire «l'étranger proche »- et s'oppose aux aspirations centrifuges qui touchent le Caucase et l'Europe orientale.

Opérée de façon continue, l'extension de l'OTAN et de l'UE jusqu'aux frontières de la Russie marque un recul de la puissance moscovite sur ses flancs occidentaux et méridionaux. Au sud, les pays du Caucase et d'Asie centrale ont signé des accords avec l'OTAN (Partenariat pour la paix). Mais seul le gouvernement géorgien s'est déclaré favorable à une adhésion à court terme à l'organisation (Serrano, 2008) ${ }^{7}$. La Russie combat cette perspective qui conclurait la translation géopolitique géorgienne et qui permettrait aux puissances occidentales d'accroître leur présence à ses marges. Pourtant, les autorités russiennes n'avaient pas été hostiles à l'installation de bases militaires états-uniennes, françaises ou allemandes en Asie centrale dans le cadre de la guerre en Afghanistan. Quoi qu'il en soit, la Géorgie bénéficie d'une aide états-unienne importante, notamment du point de vue militaire, à travers un soutien à l'effort d'armement et à la formation des officiers et des soldats. À l'échelle régionale, la constitution d'un continuum prooccidental a également pris la forme d'une organisation initiée par les Etats-Unis, le GUAM (Géorgie-Ukraine-Azerbaïdjan-Moldavie), dont l'ambition affichée - consolider la démocratie et asseoir le développement économique dans un cadre capitaliste - renvoie à deux éléments centraux de la «transition », telle qu'elle a été conçue en tant que modèle téléologique au moment de la chute du bloc socialiste. Malgré sa situation géographique périphérique, le Caucase a par ailleurs été intégré en 2004 à la politique de voisinage de l'UE. Les Européens interviennent toutefois depuis les années 1990, à travers notamment 
le programme TRACECA qui, grâce à la rénovation des infrastructures de transport, ambitionne de développer un corridor de transport alternatif entre l'Asie centrale, le Caucase et l'Europe.

Les pays du Caucase participent également à plusieurs organisations supra-étatiques élaborées autour de la Russie, au premier rang desquelles, la CEI. Toutefois, devant l'occupation militaire de son territoire, la Géorgie a décidé de quitter cette organisation. En ce sens, bien qu'inachevé, le repositionnement géopolitique de la Géorgie se poursuit en direction de l'Occident, malgré la riposte militaire russienne, d'autant plus que les pays de l'UE, en particulier les pays d'Europe orientale, sont déterminés à construire un partenariat privilégié avec ce pays. D'ailleurs, à l'échelle de l'espace géopolitique postsoviétique, les Pays Baltes ont, avec l'Ukraine, manifesté un soutien actif à la Géorgie et au régime de M. Saakachvili ; un second bloc rassemblant les républiques d'Asie centrale (Kazakhstan, Kirghizstan, Ouzbékistan, Tadjikistan) et la Biélorussie a à l'inverse adopté une position pro-russe, sans toutefois reconnaître l'indépendance de l'Ossétie du Sud et de l'Abkhazie, en vertu de leur position sur le Kosovo.

Les luttes d'influence internationales pénètrent la vie politique nationale géorgienne. Le renversement d'E. Chevardnadze au cours de la « révolution des roses » a été caractérisé, de même que la «révolution orange » en Ukraine, par l'implication d'ONG occidentales souhaitant «exporter » la démocratie et «occidentaliser » les pays d'Europe orientale (Pétric, 2008). Ce renouvellement du personnel politique, permis par l'abandon d'E. Chevardnadze par ses soutiens occidentaux, marque également l'arrivée au pouvoir d'une génération formée en Europe et aux Etats-Unis, la plupart du temps dans le cadre de programmes gouvernementaux, et acquise aux idéologies dominantes dans ces pays. Ces événements sont donc apparus comme une menace sur la stabilité de l'équipe gouvernementale et pour l'assise géopolitique de la Russie. À la différence de l'Ukraine, son action en Géorgie est toutefois limitée car les partis d'opposition sont favorables au rapprochement avec l'Occident, opinion largement partagée par la population. Ces conditions font que les Etats-Unis et l'UE disposent d'un allié fidèle dans le Caucase, dont le crédit a toutefois été affecté par la guerre de l'été de 2008. Sans remettre en cause le soutien des puissances occidentales, les événements de l'été 2008 semblent susciter une réflexion sur la nature de l'alliance à construire avec la Géorgie. En particulier, des réticences sont apparues dans les chancelleries occidentales devant la perspective d'intégrer dans l'OTAN et dans l'UE un pays dont la situation demeure très instable.

\section{Entre la Caspienne et la Méditerranée : des itinéraires concurrents pour les hydrocarbures}

27 Les rivalités géopolitiques entre les Etats-Unis et la Russie présentent une dimension économique et concernent en particulier l'exploitation et le contrôle des ressources, notamment dans le domaine de l'énergie. Du fait de l'enclavement des gisements caucasiens et centre-asiatiques, la maîtrise des exportations des hydrocarbures de la Caspienne par le Caucase est ainsi devenue un élément majeur du nouveau "Grand Jeu », alors même que la production pétrolière et gazière de l'Azerbaïdjan, du Kazakhstan et du Turkménistan tend à s'accroître. Deux voies d'exportation traversent d'est en ouest le Caucase : l'une emprunte le piémont septentrional, qui est localisé en Russie, et débouche sur le littoral pontique à Novorossiysk et Tuapse; l'autre longe le versant méridional du grand Caucase et se divise après Tblissi en un axe aboutissant aux ports géorgiens de la 
Mer Noire (Batumi, Supsa, Poti, Kulevi) et un axe parvenant à Ceyhan, port turc situé sur la Méditerranée (carte 7). Ce réseau a connu de profondes évolutions en raison de la construction de plusieurs oléoducs depuis les années 1990, à l'initiative des entreprises pétrolières nationales (State oil compagny of Azerbaijan (SOCAR), Rosneft, etc.) et transnationales (BP, Chevron, Total, etc.), d'une part, et des États (Russie, Etats-Unis, Azerbaïdjan, Géorgie, Turquie, etc.), d'autre part. Concurrentes, les nouvelles infrastructures augmentent la capacité de transport et dessinent de nouvelles voies d'exportation.

Carte 7

LES ENJEUX PÉTROLIERS DANS LE CAUCASE

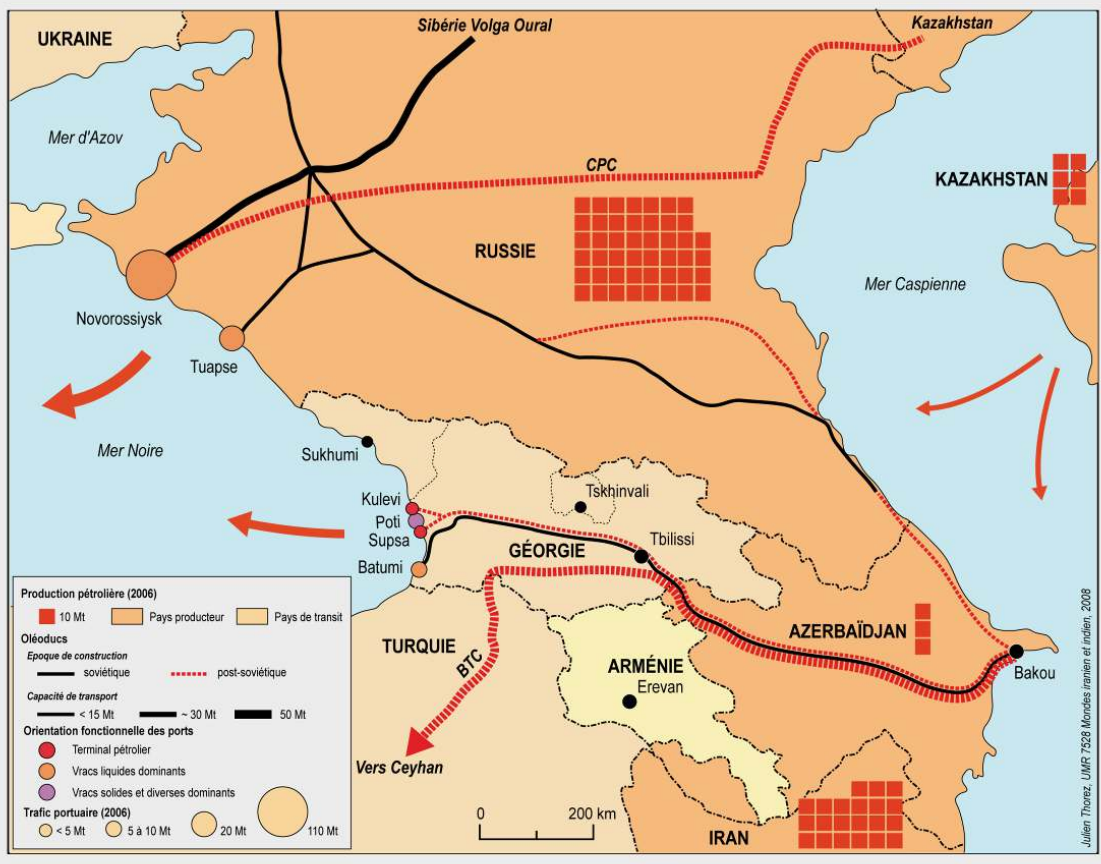

Au nord, la voie russienne a été confortée par l'ouverture en 1997 d'une conduite d'une capacité annuelle de $5 \mathrm{Mt}$ connectant Bakou au réseau russien et surtout par l'inauguration en $2001 \mathrm{du}$ Caspian Pipeline Consortium (CPC). Long de $1510 \mathrm{~km}$, cet oléoduc par lequel ont transité 32,6 Mt en 2007 relie les gisements kazakhstanais (Tenguiz) à Novorossiysk. Au sud, deux tubes traversant le territoire géorgien ont été mis en service : l'oléoduc Baku-Supsa, qui a été ouvert en 1999, dont l'itinéraire longe la frontière de l'Ossétie du Sud et double l'oléoduc approvisionnant Batumi ; l'oléoduc Bakou-Tbilissi-Ceyhan (BTC), qui constitue la principale évolution structurelle du réseau. Exploité depuis 2005, le BTC, dont la capacité de transport annuelle atteint $50 \mathrm{Mt}$, permet de contourner les détroits turcs et surtout d'éviter la Russie et l'Iran (de même que l'Arménie). Si la politique des États peut différer de la stratégie des entreprises transnationales, la construction du BTC, initiative fortement soutenue par les États-Unis ${ }^{8}$, a relevé d'une ambition commune aux différents acteurs : s'affranchir politiquement et économiquement de la Russie. En renforçant l'indépendance de l'Azerbaïdjan et de la Géorgie, d'une part, et en affirmant l'influence des puissances et des entreprises occidentales dans le Caucase, d'autre part, l'inauguration de cet axe alternatif transforme en effet les équilibres géopolitiques régionaux, au détriment de la Russie, laquelle voit son 
rôle de pays de transit limité. Toutefois, les conduites d'hydrocarbures sud-caucasiennes n'ont pas été la cible d'opérations militaires russiennes durant la guerre d'août 2008.

En revanche, l'instabilité née du conflit menace la position géo-économique de la Géorgie. Le Kazakhstan, dont l'implication est croissante dans l'économie nationale, a ainsi décidé de suspendre plusieurs projets d'investissements (raffinerie de pétrole à Batoumi, terminal céréalier à Poti), tout en maintenant cependant sa volonté d'exporter une part modeste - de sa production de pétrole par l'oléoduc Bakou-Tblissi-Ceyhan à compter de la fin de l'année 2008. De même, des informations ont fait état de réflexions pour construire via l'Arménie le gazoduc Caspienne-Méditerranée dont le tracé prévoyait initialement de transiter par la Géorgie.

Tableau 4 - Le pétrole dans le bassin caspien

\begin{tabular}{|l|c|c|c|c|}
\hline & $\begin{array}{c}\text { Production en } \\
2006(\mathrm{en} \mathrm{Mt)}\end{array}$ & $\begin{array}{c}\text { Part de la } \\
\text { production mondiale }\end{array}$ & $\begin{array}{c}\text { Réserves } \\
\text { prouvées } \\
\text { (en Mt) }\end{array}$ & $\begin{array}{c}\text { Part des réserves } \\
\text { mondiales }\end{array}$ \\
\hline Azerbaïdjan & 32,5 & $0,8 \%$ & 1000 & $0,6 \%$ \\
Kazakhstan & 66,1 & $1,7 \%$ & 5500 & $3,3 \%$ \\
Ouzbékistan & 5,4 & $0,1 \%$ & 100 & 100 \\
Turkménistan & 8,1 & $0,2 \%$ & 6700 & $0,1 \%$ \\
Caucase et Asie centrale & 112,1 & $2,8 \%$ & 10900 & $4,1 \%$ \\
Russie & 480,5 & $12,3 \%$ & & $7,8 \%$ \\
\hline
\end{tabular}

Source : British Petroleum Statistical Review of World Energy 2007

Tableau 5 -Le gaz dans le bassin caspien

\begin{tabular}{|c|c|c|c|c|}
\hline & $\begin{array}{l}\text { Production en } \\
\qquad 2006 \\
\left(\mathrm{en} \mathrm{Md} \mathrm{m}^{3} \text { ) }\right.\end{array}$ & $\begin{array}{c}\text { Part de la production } \\
\text { mondiale }\end{array}$ & $\begin{array}{l}\text { Réserves prouvées } \\
\quad\left(\mathrm{en} \mathrm{Md} \mathrm{m}^{3}\right)\end{array}$ & $\begin{array}{c}\text { Part des réserves } \\
\text { mondiales }\end{array}$ \\
\hline Azerbaïdjan & 6,3 & $0,2 \%$ & 1350 & $0,7 \%$ \\
\hline Kazakhstan & 23,9 & $0,8 \%$ & 3000 & $1,7 \%$ \\
\hline O uzbékistan & 55,4 & $1,9 \%$ & 1870 & $1,0 \%$ \\
\hline Turkménistan & 66,2 & $2,2 \%$ & 2860 & $1,6 \%$ \\
\hline Caucase et Asie centrale & 151,8 & $5,1 \%$ & 9080 & $5,0 \%$ \\
\hline Russie & 612,1 & $21,3 \%$ & 47650 & $26,3 \%$ \\
\hline
\end{tabular}

Source : British Petroleum Statistical Review of World Energy 2007

Quoiqu'il en soit, la dimension symbolique et politique du contrôle des voies caucasiennes d'évacuation des hydrocarbures de la Caspienne vers le marché mondial semble primer sur les enjeux économiques voire strictement stratégiques. D'une part, la région n'assure qu'une part réduite de la production de gaz et surtout de pétrole - en 2006, les pays l'Asie centrale et le Caucase n'ont fourni que $2,8 \%$ du pétrole et $5,1 \%$ du gaz produits dans le monde (tableaux 4 et 5). Disposant de réserves relativement limitées, la région caspienne s'apparente en ce sens à un foyer secondaire à l'échelle mondiale, quoique les pays européens souhaitent accroître leurs importations depuis l'Azerbaïdjan, le Kazakhstan et le Turkménistan à travers le projet de gazoduc Nabucco. D'autre part, la voie sudcaucasienne ne constitue qu'une des routes alternatives à la voie russienne du point de vue des pays d'Asie centrale. Ces derniers ont en effet conclu des accords avec l'Iran et la Chine pour développer les voies méridionales et orientales de désenclavement. De ce fait, si les exportations vers et via l'Iran ne concernent qu'une part modeste de la production 
caspienne, la Chine apparaît désormais comme un acteur majeur en Asie centrale. La voie orientale d'exportation des hydrocarbures connaît un essor rapide, à la suite de la mise en exploitation d'un oléoduc reliant les gisements kazakhstanais à la frontière chinoise, tandis qu'un important gazoduc est en construction pour approvisionner le Xinjiang depuis le Turkménistan, l'Ouzbékistan et le Kazakhstan.

\section{Conclusion}

La guerre de l'été 2008 présente un bilan négatif pour la plupart des protagonistes impliqués dans les rivalités géopolitiques caucasiennes locales, régionales, nationales et internationales. La Géorgie n'a pas recouvré l'intégralité de son territoire, tout en altérant sa fiabilité auprès de ses alliés occidentaux, au point de remettre en question ses perspectives d'intégration dans l'OTAN et l'UE. Pour sa part, la Russie, à travers son engagement et sa victoire militaires, affirme sa position dans son « étranger proche » face aux velléités états-uniennes et européennes. Mais la rupture géopolitique avec la Géorgie semble durable, d'autant plus que les conditions de la reconnaissance de l'indépendance de l'Abkhazie et de l'Ossétie du Sud autorisent la puissance coloniale à empiéter de facto sur le territoire géorgien. Du point de vue des Etats-Unis et de l'Union Européenne, tout en mettant en évidence des formes d'interdépendance économique fondées sur l'énergie, le conflit a menacé les relations avec la Russie, sans permettre une avancée réelle de leur influence dans le Caucase et en Asie centrale. Par ailleurs, le recours à la guerre traduit l'échec de la diffusion du modèle politique et territorial promu par les instances européennes, lequel repose sur la coopération, la négociation et la paix. En revanche, les combats, les victimes, les réfugiés ossètes et géorgiens ont replongé les populations du Caucase dans la crise des indépendances, en ravivant le spectre du chaos post-soviétique.

\section{BIBLIOGRAPHIE}

Atlas Gruzinskoj SSR [Atlas de la R.S.S. de Géorgie], 1964, Moscou-Tblissi, GUGK, 269 p.

Beroutchachvili, N, Radvanyi, J, 1996. Atlas géopolitique du Caucase, Paris, Publications des Langues'O.

Cadiot, J, 2007. Le Laboratoire impérial. Russie-URSS 1860-1940, Paris, CNRS éditions, 267 p.

Cornell, S E, 2002. Autonomy as a source of conflict - Caucasian conflicts in theoretical perspectives, World Politics, $\mathrm{n}^{\circ}$ 54, p. 245-276.

German, T C, 2006. Le conflit en Ossétie du Sud : la Géorgie contre la Russie, Politique étrangère, n $\circ 1$, p. 51-64.

Gordadze, T, 2001. La Géorgie et ses « hôtes ingrats », Critique internationale, vol. 10, n 1, p. 161-176.

King, C, 2001. The benefits of ethnic war - Understanding Eurasia's unrecognized states, World Politics, $n^{\circ}$ 53, p. 524-552. 
International Crisis Group, 2008. Russia vs Georgia : The Fallout, Bruxelles-Tbilissi, Europe Report $\mathrm{n}^{\circ} 95,45 \mathrm{p}$.

Iskanderian, A, 2004. Kavkaz-Rossiâ : migraciâ legal'naâ i illegal'naâ [Caucase-Russie : migration légale et illégale], Erevan, Kismi, 164 p.

Lynch, D, 2002. Separatist states and post-soviet conflict, International Affairs, vol. 78, $\mathrm{n}^{\circ} 4$, p. 831-848.

Pétric, B, 2008. À propos des révolutions de couleur et du soft power américain, Hérodote, $\mathrm{n}^{\circ} 129$, p. 7-20.

Radvanyi, J, 1990. L'URSS : régions et nations, Paris, Masson, 294 p.

Radvanyi, J, 2002. Grand Caucase, la « montagne des peuples » écartelée, Hérodote, n 107, p. 65-88

Rywkin, M, 2005. Le phénomène des « quasi-Etats ", Diogène, n² 210, p. 28-33.

Serrano, S, 2007. Géorgie - Sortie d'Empire, Paris, CNRS éditions, $342 \mathrm{p}$.

Serrano, S, 2008. Géorgie : le rêve brisé, Politique internationale, n 121, p. 153-172.

Thorez, P, 2004, Flux et déplacements dans le Caucase, Cahiers de géographie de l'université de Savoie , n' 2, p. 135-142.

\section{NOTES}

1. Fait original, l'attribution d'un statut particulier à l'Adjarie reposait sur un critère religieux et non pas national: bien que de nationalité géorgienne, la population de la région est majoritairement musulmane.

2. À la différence du nord-ouest du Caucase, la part des Russes n'a toutefois jamais été importante dans la population du Caucase du Sud et du Caucase oriental. Aussi les migrants de nationalité azérie, géorgienne et arménienne sont-ils plus nombreux en Russie que les migrants russes originaires des pays du Caucase du Sud.

3. Outre la Russie, seul le Nicaragua a reconnu l'Ossétie du Sud et l'Abkhazie.

4. En 2004 , les autorités de l'Ossétie du Sud considéraient que $95 \%$ de la population avait adopté la citoyenneté russienne.

5. Pour la population d'Abkhazie et d'Ossétie du Sud, la possession d'un passeport russien était également la condition de toute mobilité internationale.

6. L'attribution des JO de 2014 à Sotchi, dont l'aéroport jouxte la frontière avec l'Abkhazie, marque la confiance du CIO dans la stabilité de la région.

7. E. Chevardnadze a exprimé dès 2000 sa volonté de voir la Géorgie intégrer l'OTAN.

8. Un représentant de haut rang de l'administration états-unienne a été présent à chaque étape importante du projet BTC (signature de l'accord, inauguration des infrastructures, etc.). 


\section{RÉSUMÉS}

En août 2008, le Caucase a été le théâtre d'une guerre opposant la Géorgie à la Russie, à l'issue de laquelle la Russie a décidé de reconnaître la souveraineté de l'Abkhazie et de l'Ossétie du Sud, régions sécessionnistes géorgiennes indépendantes de facto depuis le début des années 1990. Déclenchée par le président géorgien M. Saakachvili, cette guerre a découlé de la superposition dans le Caucase d'aspirations géopolitiques contraires. L'article aborde les enjeux de ce conflit selon une approche multiscalaire, en mettant en perspective les aspirations séparatistes abkhazes et ossètes, la politique d'unification et de modernisation de l'Etat Géorgien, la complexité de la relation post-coloniale entretenue par la Russie et la Géorgie et les rivalités géopolitiques internationales inscrites dans les réalités caucasiennes

In August 2008, after the war against Georgia, Russia decided to recognize the sovereignty of the secessionist Georgian regions of Abkhazia and south Ossetia, which are de facto independent since the early 1990's. This war, unleashed by the action of he Georgian president M. Saakashvili, was a consequence of a clash between contrasting geopolitical goals in Caucasus. This article adopts a multi-scale approach to explain the war, analyzing its various dimensions, starting with the Abkhazian and Ossetian separatisms and the Georgian policy, aimed at "unifying" and modernizing the country, but dealing as well with the complex relationship between Russia and Georgia and finally with the wider international geopolitical rivalries playing out in the Caucasus.

\section{INDEX}

Mots-clés : Caucase, État, séparatisme, frontière,

Keywords : Caucasus, State, separatism, borders, "Great Game"

\section{AUTEUR}

\section{JULIEN THOREZ}

Julien Thorez est chargé de recherche au CNRS, membre de l'UMR 7528 Mondes iranien et indien (CNRS, INaLCO, EPHE, Paris III - Sorbonne nouvelle). Il a récemment publié :

- « La construction territoriale de l'indépendance : réseaux et souveraineté en Asie centrale postsoviétique » Flux, 2007, $\mathrm{n}^{\circ} 70$.

- « Itinéraires du déracinement - L'essor des migrations de travail entre l'Asie centrale et la Russie », Espaces, populations et sociétés, 2007, $n^{\circ} 1$.

- « Bazars et routes commerciales en Asie centrale - Transformation post-soviétique et

“ mondialisation par le bas" ", Revue Européenne des Migrations Internationales, 2008, vol. 24, n $\circ 3$. 